\title{
Metabolomics in the fight against malaria
}

\author{
Jorge L Salinas ${ }^{1}$, Jessica C Kissinger ${ }^{2}$, Dean P Jones ${ }^{3}$, Mary R Galinski ${ }^{1,4} /+$ \\ 'Division of Infectious Diseases ${ }^{3}$ Division of Pulmonary Medicine, Department of Medicine ${ }^{4}$ Emory Vaccine Center, Yerkes National \\ Primate Research Center, Emory University School of Medicine, Emory University, Atlanta, GA, USA ${ }^{2}$ Department of Genetics, \\ Institute of Bioinformatics, Center for Tropical and Emerging Global Diseases, University of Georgia, Athens, GA, USA
}

Metabolomics uses high-resolution mass spectrometry to provide a chemical fingerprint of thousands of metabolites present in cells, tissues or body fluids. Such metabolic phenotyping has been successfully used to study various biologic processes and disease states. High-resolution metabolomics can shed new light on the intricacies of host-parasite interactions in each stage of the Plasmodium life cycle and the downstream ramifications on the host's metabolism, pathogenesis and disease. Such data can become integrated with other large datasets generated using top-down systems biology approaches and be utilised by computational biologists to develop and enhance models of malaria pathogenesis relevant for identifying new drug targets or intervention strategies. Here, we focus on the promise of metabolomics to complement systems biology approaches in the quest for novel interventions in the fight against malaria. We introduce the Malaria Host-Pathogen Interaction Center (MaHPIC), a new systems biology research coalition. A primary goal of the MaHPIC is to generate systems biology datasets relating to human and non-human primate (NHP) malaria parasites and their hosts making these openly available from an online relational database. Metabolomic data from NHP infections and clinical malaria infections from around the world will comprise a unique global resource.

Key words: Plasmodium - high-resolution metabolomics - animal disease models

- systems biology - omics - MaHPIC - host-pathogen interactions

The causal agent of malaria was discovered over 100 years ago. Since, clinical details relating to each Plasmodium species capable of infecting humans have been documented (Plasmodium falciparum, Plasmodium vivax, Plasmodium malariae, Plasmodium ovale and Plasmodium knowlesi), as well as morbidity and mortality statistics and basic disease findings (Baird 2013, White et al. 2013). Over the last several decades, molecular biology has enabled major advances beginning with traditional gene cloning, cell biology and pathogenesis studies (Sherman 1998), followed by the sequencing, annotation and investigation of complete genomes from several human and primate malaria parasites (Gardner et al. 2002, Carlton et al. 2008, Pain et al. 2008, Tachibana et al. 2012). Furthermore, molecular and cell biological technologies have aided the development of rapid diagnostic tests (RDTs) for clinical care and epidemiological studies (Lucchi et al. 2013, Murphy et al. 2013), the development of drugs, the monitoring of drug resistance and advanced research towards developing malaria vaccines (Biamonte et al. 2013, Heppner 2013).

Despite much meaningful progress and significant efforts to tackle these species, the remaining gaps in our understanding of the intricate relationship of Plasmo-

doi: 10.1590/0074-0276140043

Financial support: NIAID, NIH (HHSN272201200031C)

+ Corresponding author: mgalins@emory.edu

Received 6 February 2014

Accepted 11 March 2014 dium with its host remain a barrier in the fight against malaria (Galinski \& Barnwell 2008, Mueller et al. 2009, Alonso et al. 2011). Relatively few specific host-parasite interactions are currently known for malaria (Beiting \& Roos 2011, Reid \& Berriman 2013), let alone a deep understanding of the cascade of molecular, biological and pathogenic events that occur in each phase of the parasite's life cycle. Critically, each interaction has undefined consequences in terms of downstream biology while details of the parasite's impact on the host's immune responses and pathogenesis are not yet completely understood. The current post-genomic era of systems biology has the potential to provide scientific knowledge in greater depth than possible before (Lucchi et al. 2013) and predictably help identify new targets of intervention and improve clinical care. The benefits of systems biology approaches to specifically understand host-parasite interactions in malaria are rapidly becoming apparent and are anticipated to multiply in the near future (Le Roch et al. 2012, Galinski et al. 2013).

Systems biology comprises an increasing number of omic technologies that have become relevant for malaria research; for example, transcriptomics, proteomics, lipidomics, glycomics, epigenomics and metabolomics, among others. By combining in-depth innate and adaptive immune profiling with cell-biological and biochemical methods able to probe and visualise biological systems in action, researchers are prepared to enter the hidden world of Plasmodium like never before. The study of single omics data types has rapidly progressed to multiple and integrated omics, notably to initially reveal the parasite's transcriptome and proteome and how they relate to each other (Le Roch et al. 2004, Foth et al. 2011). 
The field of integrated omics remains relatively new, but this is clearly the challenge of the day when considering the potential benefits of making genome-wide associations involving more than two types of large omic datasets and considering the host and pathogen simultaneously (Aurrecoechea et al. 2009). PlasmoDB has been a trailblazer for illuminating the power of integrated omics by incorporating new types of omic datasets generated by the community as new technologies become available (Kissinger et al. 2002, Aurrecoechea et al. 2009). The stakes are raised with computational biologists now using such large datasets to formulate testable biological systems-based models to enhance hypothesis-driven inquiries regarding specific host-pathogen interactions, associated molecular cascades and their downstream events and consequences (Ideker et al. 2001, Voit 2012). This is a goal of the Malaria Host-Pathogen Interaction Center (MaHPIC) (systemsbiology.emory.edu), a research consortium focused on the systems biology of malaria infections in non-human primates (NHPs) and involving a growing network of scientists investigating different aspects of human clinical malaria in the field.

Here we focus on high-resolution metabolomics, one of the omics techniques embedded in the MaHPIC. We review its contribution to malaria research and its predicted value in improving our understanding of malaria pathophysiology, clinical care and malaria eradication efforts.

Metabolomics: the nuts and bolts - Metabolomics is the study of chemicals in biosystems. It has become an incredibly powerful tool to investigate metabolism indepth, its byproducts and associated networks; this applies for studying malaria infections in the context of the host. Top-down metabolomics approaches investigate thousands of metabolites, in contrast to targeted bottomup approaches focused on small numbers of specific metabolites and their biochemical relationships (Kafsack \& Llinás 2010, Jones et al. 2012). Metabolomics is revealing biochemistry processes and end products inherent within specific cells, tissues, bodily fluids, organs or whole organisms and, importantly, metabolomic data can be experimentally developed and compared using in vitro or ex vivo systems. Furthermore, metabolomics is uniquely powerful in providing measures of genome function as well as environmental exposures (e.g., unknown toxins, food and medicine intake, cosmetics, cleaning agents, exhaust fumes etc.) (Jones et al. 2012).

The latest analytic methods used in metabolomics can measure $>20,000$ chemicals in biologic samples and enable metabolic phenotyping with detail approaching that of genotyping (Uppal et al. 2013). Briefly, analyses start by using high-resolution mass spectrometry to separate and measure thousands of small molecules present in a biologic sample (typically $<100 \mu \mathrm{L}$ of serum, plasma, bone marrow, cerebrospinal fluid, urine, saliva, solid tissue etc.). Mass spectrometry detects chemicals as ions in the gas phase, expressed as mass/charge ratio. High-resolution instruments have sufficient mass resolution and mass accuracy to allow prediction of the elemental composition. When used exclusively for biological samples with advanced data extraction algorithms to reduce experimental noise, these instruments are exquisitely sensitive to detect low abundance chemicals. In consequence, these methods produce increasingly rich datasets and utilise advanced computational methods, bioinformatics and biostatistics (Soltow et al. 2010, Uppal et al. 2013) to link function of the genome to environmental challenges (including malarial infection). Statistically significant metabolites detected in a given clinical sample are compared to publicly available databases to confirm their association in known metabolic reactions (i.e., Krebs cycle, urea cycle, glycolysis etc.) (Supplementary data).

There are many additional resources available to aid in bioinformatics and biostatistics analysis of data (Aurrecoechea et al. 2009, Kanehisa et al. 2012, Xia et al. 2012). Using a top-down approach, with the analysis of thousands of data points, one can test for significant differences among groups or following treatments as a metabolome-wide association study (Osborn et al. 2013). This is visualised as a Manhattan plot of the negative $\log _{10}$ of the p-value for each metabolite (Fig. 1). Because such analyses include many comparisons, false discovery rate adjustment by a method such as that of Benjamini and Hochberg is usually appropriate. This can be indicated by a broken line, along with the appropriate criteria, e.g., $q=0.05$ (Fig. 1). The stringency is often different for discovery-based research and biomarker development. For instance, if one is interested in pathways altered following infection with $P$. falciparum, it would be appropriate to set the criterion more liberally at $q=0.2$ to avoid overlooking pathways due to small sample size or analytic variability. On the other hand, for biomarker development, greater stringency would be appropriate, such as $q=0.05$. The Emory Clinical Biomarkers Laboratory

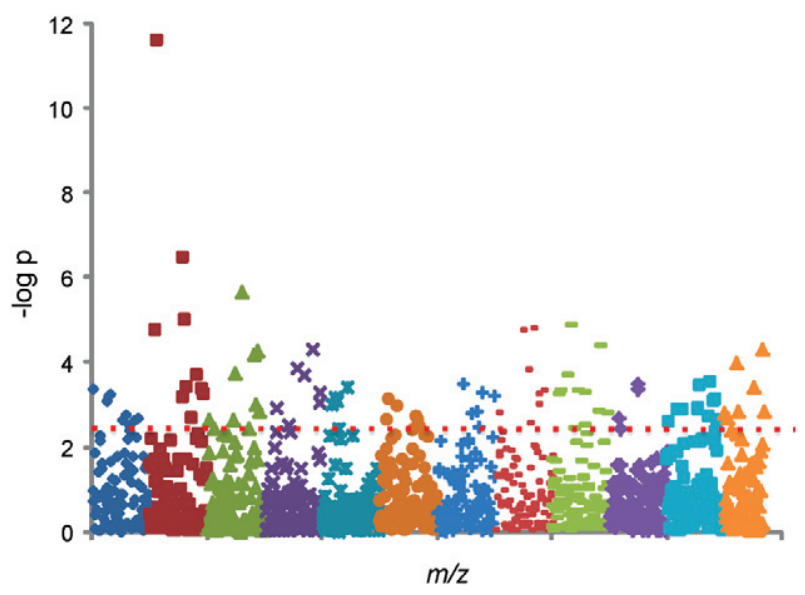

Fig. 1: this Manhattan plot depicts false detection ratio (FDR) analysis of 1,168 mass to charge ratio $(\mathrm{m} / \mathrm{z})$ features comparing 26 patients and 19 controls. The negative log p-value is plotted against the $\mathrm{m} / \mathrm{z}$ features. The X-axis represents the $\mathrm{m} / \mathrm{z}$ of the features, ordered in increasing value from left to right (85-850). The colouring of the symbols is arbitrary. A total of 94 features significantly differed between patients and controls at an FDR of $q=0.05$ (above horizontal dashed line). Adapted from Osborn et al. (2013). 
at Emory University continues to develop these technologies along with the xMSanalyzer as a pipeline and other algorithms for high-throughput analysis to study biological network activities (Uppal et al. 2013).

Metabolomics: the promise - Metabolomics will help to discern a multitude of malaria host-parasite interactions and distinguish metabolic differences between various clinical and control groups (Lakshmanan et al. 2011, Ge \& Wang 2012, Wang et al. 2013). These data become complementary to other available datasets (clinical and otherwise) and the integration of these can lead to a better understanding of biologic processes and networks associated with a disease state. In addition to dissecting the metabolic ramifications of infectious or chronic diseases, metabolomics can also analyse the effects of host interactions with symbiotic organisms (i.e., the gut microbiome) and a myriad of environmental exposures, which will differ depending on geographical and cultural norms (Jones et al. 2012). In fact, in recognition of the importance of how all such factors impact the evolving metabolomes in cells, tissues, organs and in the overall health of individuals, the concept of a phenotypic sum of internal and external factors expressed in an organism's metabolic reactions accumulated over time has become established in recent years and is known as the "exposome" (Soltow et al. 2013). Clearly, one can study host-pathogen interactions for malaria and other health conditions, but recognition of the potential impact of the exposome is important. The exposome will differ between individuals, depending on their genetics and dayto-day habits and great differences are expected from cultural, ecological, geographical and environmental exposures of peoples from around the world.

Pertinent to this discussion, metabolomics is a key scientific component of the MaHPIC systems biology project (systemsbiology.emory.edu), in addition to clinical monitoring, immune profiling, functional genomics, proteomics, lipidomics and other omic technologies that prove to be applicable (Fig. 2). The MaHPIC investigates malaria through intensive monitoring and

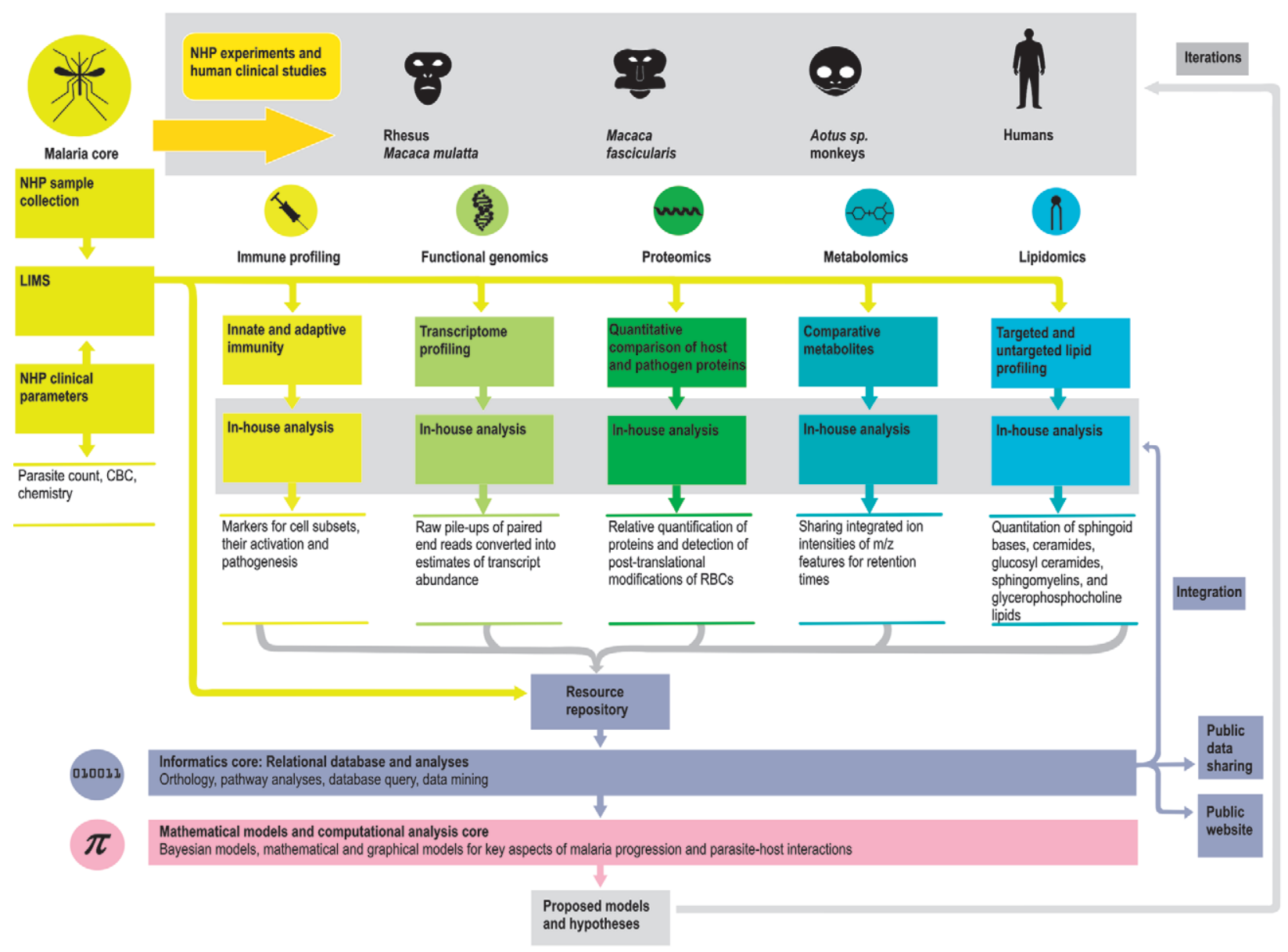

Fig. 2: Malaria Host-Pathogen Interaction Center (MaHPIC) workflow overview. Non-human primate (NHP) experiments carried out by the Malaria Core produce samples (whole blood, plasma, bone marrow and cell extracts) to be analysed by various MaHPIC scientific cores; several cores are depicted here by round symbols. Data is catalogued by the Informatics Core and further analysed by all cores as well as the Mathematical Models and Computational Analysis Core. The Metabolomics Core also analyses human plasma samples contributed by collaborators working in malaria endemic areas around the world. CBC: complete blood counts; LIMS: Laboratory Information Management System; $m / z$ : mass to charge ratio; RBC: red blood cells. 
scientific analysis of Plasmodium infections in NHPs. High-throughput data analyses combined with clinical and other metadata relating to each animal subject and pathology associated with infections permit subsequent mathematical modelling of the array of existing host-pathogen interactions and networks. Ultimately, MaHPIC's aims include data integration, experimental iterations and sharing of project data via a relational database (Kissinger et al. 2003, Aurrecoechea et al. 2009) for use by the broad scientific community (Fig. 2). Metabolomic analyses of plasma or sera samples from deidentified human clinical isolates from different malaria endemic regions of the world are highly complementary and become related to and compared alongside the data generated in the NHP models. Metabolomic information from human samples is particularly useful when they are associated with related data that can become integrated into MaHPIC's analyses and computational models: e.g., regarding the infecting species, parasitaemias, clinical status of the patients and potentially genomic, transcriptomic or immune profiling data.

The MaHPIC remains open to collaborations where the addition of high-resolution metabolomics of human samples is complementary and beneficial to ongoing clinical research studies in malaria endemic regions and where the strengthening of systems biology approaches pertinent to understanding malaria is a shared goal. Malaria researchers are, in essence, at the cusp of realising the potential for conducting systems biology research at a clinical level. Scientists can gather and assess information at specific time-points during clinical infections (e.g. upon diagnosis and after treatment) and use this information to contrast, compare and validate hypotheses. However, routine sampling of blood or other tissues, such as bone marrow, from malarial human patients is not ethically justifiable. The NHP models, with ethical review and guidelines strictly adhered to, serve a great purpose in this regard, as repeated sampling is feasible over the time-course of infections and tissue samples can also be obtained prospectively.

While malaria systems biology studies with human samples have the potential to be highly informative, NHP model systems (Craig et al. 2012, Galinski \& Barnwell 2012) have the advantage of allowing in-depth analysis of malaria infections at specific time points during an infection and over time; 100 days in the case of current MaHPIC experiments. Over a five-year period, MaHPIC infections of NHPs are designed to study the parasite metabolome at different growth phases of the parasite's life cycle and the host-parasite metabolome as it is generated in the course of infections caused by different species. Aotus nancymae monkey infections are initiated by $P$. falciparum and $P$. vivax sporozoites to best model the respective disease as it naturally occurs in humans (Collins et al. 1988). The respective model species, Plasmodium coatneyi and Plasmodium cynomolgi, are studied via sporozoite infection of Macaca mulatta (rhesus macaques) (Deye et al. 2012, Galinski et al. 2013, Moreno et al. 2013). P. knowlesi is also studied as a zoonosis of humans (Singh et al. 2004, Sabbatani et al. 2010), in its natural host (Macaca fascicularis) and in rhesus macaques. This species produces a mild resolving infection in its natural host and a severe infection that becomes lethal if not treated in the experimental rhesus macaque host. For all such infections, or co-infections (e.g., $P$. falciparum and $P$. vivax or $P$. coatneyi and $P$. cynomolgi), multiple omic datasets, clinical and immune response data and various associated metadata are being catalogued and studied to understand the progression of disease processes and illness as it relates to the infections and the evolving states of host immunity.

In malaria research, it is hoped that metabolomic differences will be instructive with regards to the pathogenesis of severe and non-severe cases of malaria and advance our knowledge about the biological differences of the Plasmodium species and their distinctive hostpathogen interactions, including host cell invasion, elements of the immune response and evasion tactics. In other instances, metabolomics may prove to be useful to distinguish the presence or activation of hypnozoites, the quiescent forms of $P$. vivax and $P$. ovale in the liver that upon activation are responsible for relapsing infections in the blood (Mueller et al. 2009, White \& Imwong 2012). The eventual analysis of hundreds of speciated samples (for infections harbouring single and multiple species of Plasmodium) from different areas of the world with different cultures, dietary habits, environmental exposures, ecologies and transmission patterns, along with associated clinical and other experimental datasets is predicted to add a new perspective to our current knowledge of malaria.

It is critical to recognise that the metabolome is in constant flux, being influenced by innumerable endogenous and exogenous factors, malaria infection being but just one. The Plasmodium parasites alone have unique effects depending on the infecting species, strain(s) and the specific host makeup. In addition, there can be some variability in the experimentally determined metabolome depending upon how and under what conditions samples are handled, processed or stored. For the MaHPIC, frozen clinical samples are used for metabolomics analyses and ideally without being subjected to repeated freeze-thaw processes that may result in the alteration or degradation of some metabolites or in the persistence of unnatural byproducts or artifacts. When planning prospective studies, it will be wise for investigators to establish standard operating procedures for the collection and freezing of clinical samples that are slated for metabolomics to best ensure the development of data that most closely mimics the metabolome of the in vivo sample at the time of collection. This is especially important when considering the varied circumstances, temperatures, clinical environments and experimental conditions where samples may be collected, especially under endemic field conditions and the potential time differences between sample acquisition and freezing.

Metabolomics to understand malaria biology Blood stages - Over the last decade, several independent groups have endeavoured to characterise the metabolic profile of Plasmodium species, with a predominance of the literature focusing in P. falciparum. Teng et al. 
(2009) identified $>50$ parasite-specific metabolites in $P$. falciparum blood-stage in vitro cultures. Also using cultures, Olszewski et al. (2009) was able to quantify the levels of approximately 200 known metabolites in P. falciparum during the intra-erythrocytic stage, describing for the first time the conversion of arginine to ornithine by parasite arginase.

Liver and mosquito stages - To our knowledge, no studies to date have reported the use of metabolomics to understand the biology of either the parasite's liver or mosquito stages. Liver stages are not as readily accessible as the blood forms and there is still a need for the use and improvement of in vitro culture techniques and animal models. NHP models remain especially critical for the Plasmodium species that form hypnozoites, in particular $P$. vivax and its simian malaria "cousin", $P$. cynomolgi, as a model (Dembélé et al. 2011, 2014, Craig et al. 2012, Galinski \& Barnwell 2012, Barnwell \& Galinski 2014). Studies in NHPs liver tissue are hoped to help identify metabolites to distinguish primary liverstage forms, hypnozoites and activated hypnozoites in these species. Once key metabolic pathways are known in the animal models, these could be studied in humans in search of biomarkers and therapeutic targets.

Less studied species of Plasmodium - As the genomes of the less common and evolutionarily diverse Plasmodium species (P. malariae and P. ovale) (Alemu et al. 2013, Douglas et al. 2013) have not yet been fully described, metabolomics may provide a critical complement to genetics to understand the biology of these species. This would be possible, if indeed the metabolome represents a phenotype or readout of the Plasmodium genotype. For example, similar metabolic pathways detected between two Plasmodium species (where only one has a known genome) would represent key evidence of the presence of similar genotypic information in the species with the yet unknown genome. Metabolomics can also be used to accelerate our understanding of the pathophysiology of the less common species as well as provide potential diagnostic markers that would help greatly in avoiding misdiagnoses (Imwong et al. 2009, malERA 2011).

Clinical implications in malaria - Diagnostics - Currently, malaria diagnostic tests are mainly via blood smear microscopy, antigen-based RDTs and nucleic acid amplification (Murphy et al. 2013). It is possible that metabolomics can yield novel biomarkers for use in new diagnostic tools. Lakshmanan et al. (2012) demonstrated a plant like alpha linolenic acid in P. falciparum. Sengupta et al. (2011) carried out a study analysing urine of $P$. vivax infected, uninfected individuals and febrile controls and found that ornithine was differentially present in infected individuals. The use of metabolomics for the discovery of diagnostic biomarkers will ideally become focused on non-invasive sampling such as saliva or urine samples, which will improve feasibility, compliance and possibly cost. Specific biomarkers for each species and for particular disease states (severe vs. non severe, cerebral malaria, asymptomatic carriage of liver forms etc.) could be developed following this approach. Such bio- markers could also specifically help detect asymptomatic travellers returning to non-endemic areas and be used as a tool to identify individuals in need of therapy to prevent the onset of patent clinical malaria.

Prognostics - Olszewski et al. (2009) used metabolomics to study P. falciparum infections and postulated a potential link of parasite-induced hypoargininaemia with the development of cerebral malaria. Basant et al. (2010) used the $P$. berghei mouse model of cerebral malaria to study the metabolic alterations in urine, serum and brain. They observed metabolic alterations that were different in female and male hosts suggesting that the host sex may affect disease prognosis and treatment. More recently, Ghosh et al. (2013) used the same model to assess the metabolism of kidney and spleen tissue from infected mice. They discovered distinct lipid and tricyclic acid metabolism in infected mice with cerebral malaria. Similar studies carried out on infected humans with distinct forms of severe malaria (i.e., severe anaemia, neurological involvement and respiratory distress) could lead to the discovery of prognostic biomarkers. Metabolomics holds promise as a means to bring together expert clinicians and basic scientists to accelerate progress with our understanding of clinical malaria, its pathophysiology and severity. One such application is the use of metabolomics to address the complex issue of $P$. vivax severity (Lacerda et al. 2012) and how it differs from P. falciparum severity, where in both instances a myriad of host and parasitic factors are likely to play a role. Metabolomics may also prove useful for differentiating those individuals ill due to exacerbation of undiagnosed comorbidities vs. those due specifically to malaria.

Therapeutics - By detecting unique metabolic pathways inherent to the parasite in its different stages (liver or blood), metabolomics provides an opportunity to discover novel candidate therapeutic targets. For example, the use of metabolomics led to the identification of isoprenoid (Couto et al. 1999), carotenoid (Tonhosolo et al. 2009) and glycerol (Lian et al. 2009) biosynthesis pathways which were not known to occur in P. falciparum. Metabolomics could also help discover metabolic pathways inherent to latent infections (hypnozoites) that could be addressed pharmacologically, possibly providing alternatives to primaquine, currently the only US Food and Drug Administration approved medication for hypnozoites. Primaquine has the disadvantage of being associated with significant side effects in individuals with glucose 6-phosphate dehydrogenase deficiency and new drugs without this liability would be greatly welcomed (Howes et al. 2013).

Biomarkers of drug resistance - There is increasing concern regarding $P$. falciparum and $P$. vivax resistance to current medications (Ariey et al. 2014). One possible mechanism of resistance to anti-malarials is the modification of Plasmodium metabolism. As such, metabolomics would be an opportune new strategy to investigate and develop biomarkers of resistance. These biomarkers would be of utmost relevance to the clinician treating the individual patient, but would also be 
of use to the epidemiologist attempting to measure the prevalence of resistance in a given geographic area or population. Such indicators, if available, would be quite useful for policy decisions.

Metabolomics and malaria eradication - Today's global agenda for malaria eradication requires the intensive monitoring of Plasmodium parasites, their transmission and cases at a population level along with strategic elimination strategies (Alonso et al. 2011). There are multiple possible targets of intervention in the Plasmodium life cycle: mosquito stages, liver stages and blood stages (asexual and sexual infected red blood cells). These various life forms can be better characterised using metabolomics technologies with the benefit of the possible detection of biomarkers relating to their different stages of growth, development and transformation.

Ecologic studies - Measuring the genetic diversity in parasite populations has been postulated as a useful tool in the study of malaria/human ecology (Herrera et al. 2012). This strategy provides insight into the impact of ecologic factors (i.e. geographic barriers to mosquito dispersion, human migration patterns etc.) on malaria transmission and persistence in a given region. Similarly, we postulate that metabolomic variations in parasitic populations would likely include the effects of such ecologic factors and would add the effect of a myriad of other environmental factors, thus providing a strategy complementary to the currently ongoing eradication efforts.

Elimination strategies - It is hoped that metabolomics will aid the diagnosis of asymptomatic carriage of Plasmodium hypnozoites, which is critical in drug administration efforts aimed at decreasing this hidden biomass and reducing the prospects for relapsing infections and mosquito transmission (Hsiang et al. 2013).

Malaria vaccines - Systems biology approaches are being increasingly applied in the field of vaccinology, including malaria vaccine development where new avenues forward are required (Grimm \& Ackerman 2013, Heppner 2013). The use of metabolomics in the testing of malaria vaccine candidates may aid the understanding of immune responses upon vaccination. Importantly, various high-throughput omics and immune profiling strategies, including metabolomics, benefit from current technologies that utilise small sample volumes amenable from trial participants (Galinski et al. 2014). Predictive systems biology strategies, recently coined "systems vaccinology", generate and integrate large datasets to bring novel perspectives to the study of vaccines and their effectiveness (Pulendran et al. 2010, Li et al. 2014, Ravindran et al. 2014). Metabolomic signatures will predictably be of increasing value in helping to pinpoint the immune system pathway(s) affected by specific malaria vaccine candidates and serve as biomarkers of vaccine effectiveness.

Open international collaborations - This is the beginning of an era of unprecedented datasets, with thousands of data points. As systems biology approaches gain traction, the malaria research community will be faced with a data avalanche, with great prospects anticipated for revealing new targets of intervention in the fight against malaria. Metabolomics approaches are expected to expand through the future and potentially become commonplace in hospitals and clinics, not just for diagnostic purposes, but to provide predictive health insights and advice towards the prevention of illness and disease. High-throughput technologies and capabilities are becoming utilised in an increasing number of laboratories worldwide and through collaborations.

The MaHPIC has begun to establish an interactive network of scientists interested in malaria systems biology and metabolomics. A primary goal of the MaHPIC is to work collaboratively and generate global, integrated datasets that can be accessed by researchers from various fields, with both new and existing tools. Data from the MaHPIC will be released to the most appropriate public repositories including PlasmoDB (Aurrecoechea et al. 2009), the National Center for Biotechnology Information, GenBank, Gene Expression Omnibus etc. Links to data as they become available will be established at systemsbiology.emory.edu.

Just as the genomics era attracted individuals with unique skills in bioinformatics, systems biology is attracting individuals with expertise in biology and mathematics. Carrying out metabolomics analyses specifically requires in-depth knowledge in biochemistry and biostatistics. Students and fellows will have many opportunities to mine the data and workshops will become helpful to expedite training and the development of programs to streamline analyses. Ultimately, the power of the data should become a magnet for scientific leaders. Many experts will be needed to make sense of the data and reap the benefits.

Malaria remains one of the largest global health problems with an estimated 627,000 deaths and 207 million cases annually (WHO 2013). Despite over 100 years of research to understand, prevent, diagnose and treat malaria, over two billion people in close to 100 countries remain at risk of infection, mainly in resource-limited settings. Critical advances have been made in prevention, detection, prognosis and cure, but elimination is hampered by our incomplete understanding of the complex nature of the disease. Five species of Plasmodium cause malaria in humans and the intricate life cycle, human immune response and multitude of human-parasite interactions that occur during the infections, contribute to the challenges of this public health problem. Genomics capabilities have advanced to provide the tools to help understand the genetic bases of host susceptibility and pathogen life cycle. Metabolomics has the unique power of revealing thousands of metabolites that reflect the function of parasite and host genomes, as well as environmental exposures. In summary, the coordinated use of metabolomics with other systems biology approaches holds much promise for the identification of new targets of intervention and the development of new tools for the diagnosis, treatment and ultimate elimination of malaria. 


\section{ACKNOWLEDGEMENTS}

To Esmeralda Meyer, for her critical review of the paper, and the MaHPIC team and scientific community, for insights and inspiration.

\section{REFERENCES}

Alemu A, Fuehrer H-P, Getnet G, Tessema B, Noed1 H 2013. Plasmodium ovale curtisi and Plasmodium ovale wallikeri in North-West Ethiopia. Malar J 12: 346.

Alonso PL, Brown G, Arévalo-Herrera M, Binka F, Chitnis C, Collins F, Doumbo OK, Greenwood B, Hall BF, Levine MM, Mendis K, Newman RD, Plowe CV, Rodríguez MH, Sinden R, Slutsker L, Tanner M 2011. A research agenda to underpin malaria eradication. PLoS Med 8: e1000406.

Ariey F, Witkowski B, Amaratunga C, Beghain J, Langlois A-C, Khim N, Kim S, Duru V, Bouchier C, Ma L, Lim P, Leang R, Duong S, Sreng S, Suon S, Chuor CM, Bout DM, Ménard S, Rogers WO, Genton B, Fandeur T, Miotto O, Ringwald P, Le Bras J, Berry A, Barale J-C, Fairhurst RM, Benoit-Vical F, Mercereau-Puijalon O, Ménard D 2014. A molecular marker of artemisinin-resistant Plasmodium falciparum malaria. Nature 505: 50-55.

Aurrecoechea C, Brestelli J, Brunk BP, Dommer J, Fischer S, Gajria B, Gao X, Gingle A, Grant G, Harb OS, Heiges M, Innamorato F, Iodice J, Kissinger JC, Kraemer E, Li W, Miller JA, Nayak V, Pennington C, Pinney DF, Roos DS, Ross C, Stoeckert CJ, Treatman C, Wang H 2009. PlasmoDB: a functional genomic database for malaria parasites. Nucleic Acids Res 37: D539-D543.

Baird JK 2013. Evidence and implications of mortality associated with acute Plasmodium vivax malaria. Clin Microbiol Rev 26: 36-57.

Barnwell JW, Galinski MR 2014. Malarial liver parasites awaken in culture. Nat Med 20: 237-239.

Basant A, Rege M, Sharma S, Sonawat HM 2010. Alterations in urine, serum and brain metabolomic profiles exhibit sexual dimorphism during malaria disease progression. Malar J 9: 110.

Beiting DP, Roos DS 2011. A systems biological view of intracellular pathogens. Immunol Rev 240: 117-128.

Biamonte MA, Wanner J, Le Roch KG 2013. Recent advances in malaria drug discovery. Bioorg Med Chem Lett 23: 2829-2843.

Carlton JM, Adams JH, Silva JC, Bidwell SL, Lorenzi H, Caler E, Crabtree J, Angiuoli SV, Merino EF, Amedeo P, Cheng Q, Coulson RMR, Crabb BS, del Portillo HA, Essien K, Feldblyum TV, Fernandez-Becerra C, Gilson PR, Gueye AH, Guo X, Kang'a S, Kooij TWA, Korsinczky M, Meyer EVS, Nene V, Paulsen I, White O, Ralph SA, Ren Q, Sargeant TJ, Salzberg SL, Stoeckert CJ, Sullivan SA, Yamamoto MM, Hoffman SL, Wortman JR, Gardner MJ, Galinski MR, Barnwell JW, Fraser-Liggett CM 2008. Comparative genomics of the neglected human malaria parasite Plasmodium vivax. Nature 455: 757-763.

Collins WE, Skinner JC, Pappaioanou M, Broderson JR, Ma NS, Filipski V, Stanfill PS, Rogers L 1988. Infection of Peruvian Aotus nancymai monkeys with different strains of Plasmodium falciparum, P. vivax and P. malariae. J Parasitol 74: 392-398.

Couto AS, Kimura EA, Peres VJ, Uhrig ML, Katzin AM 1999. Active isoprenoid pathway in the intra-erythrocytic stages of Plasmodium falciparum: presence of dolichols of 11 and 12 isoprene units. Biochem J 341: 629-637.

Craig AG, Grau GE, Janse C, Kazura JW, Milner D, Barnwell JW, Turner G, Langhorne J, participants of the Hinxton Retreat Meeting on Animal Models for Research on Severe Malaria 2012. The role of animal models for research on severe malaria. PLoS Pathog 8: e1002401.
Dembélé L, Franetich JF, Lorthiois A, Gego A, Zeeman AM, Kocken $\mathrm{CH}$, Le Grand R, Dereuddre-Bosquet N, van Gemert GJ, Sauerwein R, Vaillant JC, Hannoun L, Fuchter MJ, Diagana TT, Malmquist NA, Scherf A, Snounou G, Mazier D 2014. Persistence and activation of malaria hypnozoites in long-term primary hepatocyte cultures. Nat Med 20: 307-312.

Dembélé L, Gego A, Zeeman A-M, Franetich J-F, Silvie O, Rametti A, Le Grand R, Dereuddre-Bosquet N, Sauerwein R, van Gemert G-J, Vaillant J-C, Thomas AW, Snounou G, Kocken CHM, Mazier D 2011. Towards an in vitro model of Plasmodium hypnozoites suitable for drug discovery. PLoS ONE 6: e18162.

Deye GA, Gettayacamin M, Hansukjariya P, Im-erbsin R, Sattabongkot J, Rothstein Y, Macareo L, Francisco S, Bennett K, Magill AJ, Ohrt C 2012. Use of a rhesus Plasmodium cynomolgi model to screen for anti-hypnozoite activity of pharmaceutical substances. Am J Trop Med Hyg 86: 931-935.

Douglas NM, Lampah DA, Kenangalem E, Simpson JA, Poespoprodjo JR, Sugiarto P, Anstey NM, Price RN 2013. Major burden of severe anemia from non-falciparum malaria species in southern Papua: a hospital-based surveillance study. PLoS Med 10: e1001575.

Foth BJ, Zhang N, Chaal BK, Sze SK, Preiser PR, Bozdech Z 2011. Quantitative time-course profiling of parasite and host cell proteins in the human malaria parasite Plasmodium falciparum. Mol Cell Proteomics 10: M110.006411.

Galinski MR, Barnwell JW 2008. Plasmodium vivax: who cares? Malar $J 7$ (Suppl. 1): S9.

Galinski MR, Barnwell JW 2012. Nonhuman primate models for human malaria research. In CR Abee, K Mansfield, S Tardif, T Morris (eds.), Nonhuman primates in biomedical research, 2nd ed., Academic Press, Boston, p. 299-323.

Galinski MR, Meyer EVS, Barnwell JW 2013. Plasmodium vivax: modern strategies to study a persistent parasite's life cycle. $A d v$ Parasitol 81: 1-26.

Galinski MR, Tirouvanziam RM, Moreno A 2014. Plasmodium vivax vaccine surrogate markers of protection: dawning of a new era. In G Corradin, H Engers (eds.), Malaria vaccine development: over 40 years of trials and tribulations, Future Medicine, London, p. 29-47.

Gardner MJ, Hall N, Fung E, White O, Berriman M, Hyman RW, Carlton JM, Pain A, Nelson KE, Bowman S, Paulsen IT, James K, Eisen JA, Rutherford K, Salzberg SL, Craig A, Kyes S, Chan M-S, Nene V, Shallom SJ, Suh B, Peterson J, Angiuoli S, Pertea M, Allen J, Selengut J, Haft D, Mather MW, Vaidya AB, Martin DMA, Fairlamb AH, Fraunholz MJ, Roos DS, Ralph SA, McFadden GI, Cummings LM, Subramanian GM, Mungall C, Venter JC, Carucci DJ, Hoffman SL, Newbold C, Davis RW, Fraser CM, Barrell B 2002. Genome sequence of the human malaria parasite Plasmodium falciparum. Nature 419: 498-511.

Ge Y, Wang TJ 2012. Identifying novel biomarkers for cardiovascular disease risk prediction. J Intern Med 272: 430-439.

Ghosh S, Sengupta A, Sharma S, Sonawat HM 2013. Metabolic perturbations of kidney and spleen in murine cerebral malaria: (1)H NMR-Based Metabolomic Study. PLoS ONE 8: e73113.

Grimm SK, Ackerman ME 2013. Vaccine design: emerging concepts and renewed optimism. Curr Opin Biotechnol 24: 1078-1088.

Heppner DG 2013. The malaria vaccine - status quo 2013. Travel Med Infect Dis 11: 2-7.

Herrera S, Quiñones ML, Quintero JP, Corredor V, Fuller DO, Mateus JC, Calzada JE, Gutierrez JB, Llanos A, Soto E, Menéndez C, Wu Y, Alonso P, Carrasquilla G, Galinski M, Beier JC, Arévalo-Herrera M 2012. Prospects for malaria elimination in non-Amazonian regions of Latin America. Acta Trop 121: 315-323. 
Howes RE, Dewi M, Piel FB, Monteiro WM, Battle KE, Messina JP, Sakuntabhai A, Satyagraha AW, Williams TN, Baird JK, Hay SI 2013. Spatial distribution of G6PD deficiency variants across malaria-endemic regions. Malar J 12: 418.

Hsiang MS, Hwang J, Tao AR, Liu Y, Bennett A, Shanks GD, Cao J, Kachur SP, Feachem RG, Gosling RD, Gao Q 2013. Mass drug administration for the control and elimination of Plasmodium vivax malaria: an ecological study from Jiangsu province, China. Malar J 12: 383.

Ideker T, Thorsson V, Ranish JA, Christmas R, Buhler J, Eng JK, Bumgarner R, Goodlett DR, Aebersold R, Hood L 2001. Integrated genomic and proteomic analyses of a systematically perturbed metabolic network. Science 292: 929-934.

Imwong M, Tanomsing N, Pukrittayakamee S, Day NPJ, White NJ, Snounou G 2009. Spurious amplification of a Plasmodium vivax small-subunit RNA gene by use of primers currently used to detect P. knowlesi. J Clin Microbiol 47: 4173-4175.

Jones DP, Park Y, Ziegler TR 2012. Nutritional metabolomics: progress in addressing complexity in diet and health. Аnnu Rev Nutr 32: 183-202.

Kafsack BFC, Llinás M 2010. Eating at the table of another: metabolomics of host-parasite interactions. Cell Host Microbe 7: 90-99.

Kanehisa M, Goto S, Sato Y, Furumichi M, Tanabe M 2012. KEGG for integration and interpretation of large-scale molecular data sets. Nucleic Acids Res 40: D109-D114.

KEGG 2011. Kyoto Encyclopedia of Genes and Genomes. Available from: kegg.jp.

Kissinger JC, Brunk BP, Crabtree J, Fraunholz MJ, Gajria B, Milgram AJ, Pearson DS, Schug J, Bahl A, Diskin SJ, Ginsburg H, Grant GR, Gupta D, Labo P, Li L, Mailman MD, McWeeney SK, Whetzel P, Stoeckert CJ, Roos DS 2002. The Plasmodium genome database. Nature 419: 490-492.

Kissinger JC, Gajria B, Li L, Paulsen IT, Roos DS 2003. ToxoDB: accessing the Toxoplasma gondii genome. Nucleic Acids Res 31: 234-236.

Lacerda MVG, Mourão MPG, Alexandre MAA, Siqueira AM, Magalhães BML, Martinez-Espinosa FE, Filho FSS, Brasil P, Ventura AMRS, Tada MS, Couto VSCD, Silva AR, Silva RSU, Alecrim MGC 2012. Understanding the clinical spectrum of complicated Plasmodium vivax malaria: a systematic review on the contributions of the Brazilian literature. Malar J 11: 12.

Lakshmanan V, Rhee KY, Daily JP 2011. Metabolomics and malaria biology. Mol Biochem Parasitol 175: 104-111.

Lakshmanan V, Rhee KY, Wang W, Yu Y, Khafizov K, Fiser A, Wu P, Ndir O, Mboup S, Ndiaye D, Daily JP 2012. Metabolomic analysis of patient plasma yields evidence of plant-like $\alpha$-linolenic acid metabolism in Plasmodium falciparum. J Infect Dis 206: 238-248.

Le Roch KG, Chung D, Ponts N 2012. Genomics and integrated systems biology in Plasmodium falciparum: a path to malaria control and eradication. Parasite Immunol 34: 50-60.

Le Roch KG, Johnson JR, Florens L, Zhou Y, Santrosyan A, Grainger M, Yan SF, Williamson KC, Holder AA, Carucci DJ, Yates JR, Winzeler EA 2004. Global analysis of transcript and protein levels across the Plasmodium falciparum life cycle. Genome Res 14: 2308-2318

Li S, Rouphael N, Duraisingham S, Romero-Steiner S, Presnell S, Davis C, Schmidt DS, Johnson SE, Milton A, Rajam G, Kasturi S, Carlone GM, Quinn C, Chaussabel D, Palucka AK, Mulligan MJ, Ahmed R, Stephens DS, Nakaya HI, Pulendran B 2014. Molecular signatures of antibody responses derived from a systems biology study of five human vaccines. Nat Immunol 15: 195-204.
Lian L-Y, Al-Helal M, Roslaini AM, Fisher N, Bray PG, Ward SA, Biagini GA 2009. Glycerol: an unexpected major metabolite of energy metabolism by the human malaria parasite. Malar $J$ 8: 38 .

Lucchi NW, Oberstaller J, Kissinger JC, Udhayakumar V 2013. Malaria diagnostics and surveillance in the post-genomic era. Public Health Genomics 16: 37-43.

malERA - Consultative Group on Basic Science and Enabling Technologies 2011. A research agenda for malaria eradication: basic science and enabling technologies. PLoS Med 8: e1000399.

Moreno A, Cabrera-Mora M, Garcia A, Orkin J, Strobert E, Barnwell JW, Galinski MR 2013. Plasmodium coatneyi in rhesus macaques replicates the multisystemic dysfunction of severe malaria in humans. Infect Immun 81: 1889-1904.

Mueller I, Galinski MR, Baird JK, Carlton JM, Kochar DK, Alonso PL, del Portillo HA 2009. Key gaps in the knowledge of Plasmodium vivax, a neglected human malaria parasite. Lancet Infect Dis 9: 555-566.

Murphy SC, Shott JP, Parikh S, Etter P, Prescott WR, Stewart VA 2013. Malaria diagnostics in clinical trials. Am J Trop Med Hyg 89: 824-829.

Olszewski KL, Morrisey JM, Wilinski D, Burns JM, Vaidya AB, Rabinowitz JD, Llinás M 2009. Host-parasite interactions revealed by Plasmodium falciparum metabolomics. Cell Host Microbe 5: 191-199.

Osborn MP, Park Y, Parks MB, Burgess LG, Uppal K, Lee K, Jones DP, Brantley MA 2013. Metabolome-wide association study of neovascular age-related macular degeneration. PLOS ONE 8: e72737.

Pain A, Böhme U, Berry AE, Mungall K, Finn RD, Jackson AP, Mourier T, Mistry J, Pasini EM, Aslett MA, Balasubrammaniam S, Borgwardt K, Brooks K, Carret C, Carver TJ, Cherevach I, Chillingworth T, Clark TG, Galinski MR, Hall N, Harper D, Harris D, Hauser H, Ivens A, Janssen CS, Keane T, Larke N, Lapp S, Marti M, Moule S, Meyer IM, Ormond D, Peters N, Sanders M, Sanders S, Sargeant TJ, Simmonds M, Smith F, Squares R, Thurston S, Tivey AR, Walker D, White B, Zuiderwijk E, Churcher C, Quail MA, Cowman AF, Turner CMR, Rajandream MA, Kocken CHM, Thomas AW, Newbold CI, Barrell BG, Berriman M 2008. The genome of the simian and human malaria parasite Plasmodium knowlesi. Nature 455: 799-803.

Pulendran B, Li S, Nakaya HI 2010. Systems vaccinology. Immunity 33: 516-529.

Ravindran R, Khan N, Nakaya HI, Li S, Loebbermann J, Maddur MS, Park Y, Jones DP, Chappert P, Davoust J, Weiss DS, Virgin HW, Ron D, Pulendran B 2014. Vaccine activation of the nutrient sensor GCN2 in dendritic cells enhances antigen presentation. Science 343: 313-317.

Reid AJ, Berriman M 2013. Genes involved in host-parasite interactions can be revealed by their correlated expression. Nucleic Acids Res 41: 1508-1518.

Sabbatani S, Fiorino S, Manfredi R 2010. The emerging of the fifth malaria parasite (Plasmodium knowlesi): a public health concern? Braz J Infect Dis 14: 299-309.

Sengupta A, Ghosh S, Basant A, Malusare S, Johri P, Pathak S, Sharma S, Sonawat HM 2011. Global host metabolic response to Plasmodium vivax infection: a $1 \mathrm{H}$ NMR based urinary metabonomic study. Malar J 10: 384

Sherman IK 1998. Malaria parasite biology, pathogenesis and protection, ASM Press, Washington DC, 575 pp.

Singh B, Sung LK, Matusop A, Radhakrishnan A, Shamsul SSG, Cox-Singh J, Thomas A, Conway DJ 2004. A large focus of natu- 
rally acquired Plasmodium knowlesi infections in human beings. Lancet 363: 1017-1024.

Soltow QA, Jones DP, Promislow DEL 2010. A network perspective on metabolism and aging. Integr Comp Biol 50: 844-854.

Soltow QA, Strobel FH, Mansfield KG, Wachtman L, Park Y, Jones DP 2013. High-performance metabolic profiling with dual chromatography-fourier-transform mass spectrometry (DC-FTMS) for study of the exposome. Metabolomics 9: S132-S143.

Tachibana S-I, Sullivan SA, Kawai S, Nakamura S, Kim HR, Goto N, Arisue N, Palacpac NMQ, Honma H, Yagi M, Tougan T, Katakai Y, Kaneko O, Mita T, Kita K, Yasutomi Y, Sutton PL, Shakhbatyan R, Horii T, Yasunaga T, Barnwell JW, Escalante AA, Carlton JM, Tanabe K 2012. Plasmodium cynomolgi genome sequences provide insight into Plasmodium vivax and the monkey malaria clade. Nat Genet 44: 1051-1055.

Teng R, Junankar PR, Bubb WA, Rae C, Mercier P, Kirk K 2009. Metabolite profiling of the intraerythrocytic malaria parasite Plasmodium falciparum by (1)HNMR spectroscopy. NMR Biomed 22: 292-302.

Tonhosolo R, D’Alexandri FL, de Rosso VV, Gazarini ML, Matsumura MY, Peres VJ, Merino EF, Carlton JM, Wunderlich G,
Mercadante AZ, Kimura EA, Katzin AM 2009. Carotenoid biosynthesis in intraerythrocytic stages of Plasmodium falciparum. J Biol Chem 284: 9974-9985.

Uppal K, Soltow QA, Strobel FH, Pittard WS, Gernert KM, Yu T, Jones DP 2013. xMSanalyzer: automated pipeline for improved feature detection and downstream analysis of large-scale, nontargeted metabolomics data. BMC Bioinformatics 14: 15.

Voit EO 2012. A first course in systems biology, Garland Science, New York, 496 pp.

Wang X, Zhang A, Sun H 2013. Power of metabolomics in diagnosis and biomarker discovery of hepatocellular carcinoma. Hepatology 57: 2072-2077.

White NJ, Imwong M 2012. Relapse. Adv Parasitol 80: 113-150.

White NJ, Pukrittayakamee S, Hien TT, Faiz MA, Mokuolu OA, Dondorp AM 2013. Malaria. Lancet 383: 723-735.

WHO - World Health Organization 2013. World Malaria Report 2013. Available from: who.int/malaria/publications/world_malaria report_2013/en/

Xia J, Mandal R, Sinelnikov IV, Broadhurst D, Wishart DS 2012. MetaboAnalyst 2.0 - a comprehensive server for metabolomic data analysis. Nucleic Acids Res 40: W127-W133. 


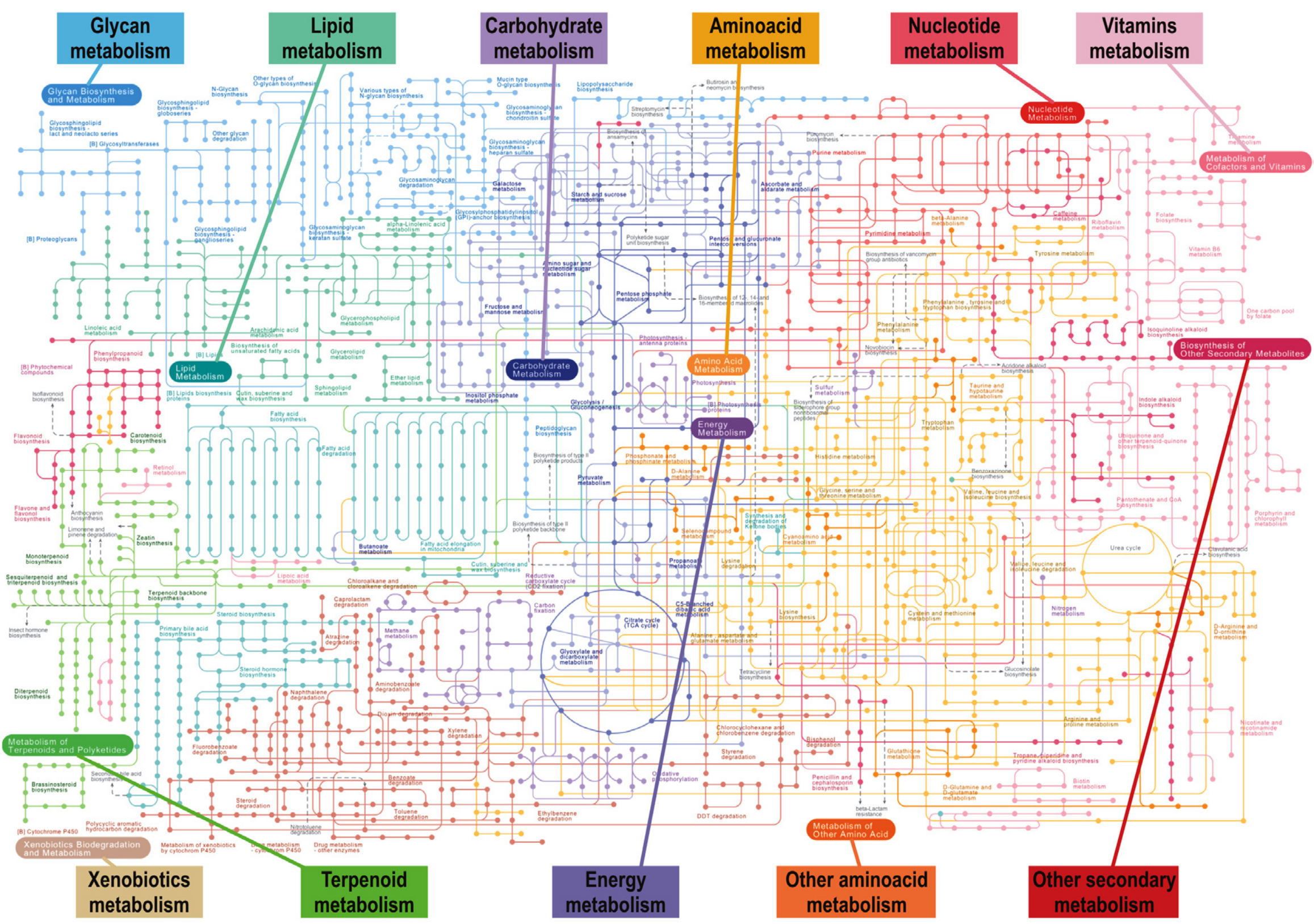

Summary of metabolic pathways as represented by the Kyoto Encyclopedia of Genes and Genomes. Adapted from KEGG (2011) and Kanehisa et al. (2012). 